\title{
Peritoneum as the sole distant metastatic site of lung adenosquamous cell carcinoma: a case report
}

\author{
Pan Yang ${ }^{1}$, Wei-Liang Li2 ${ }^{2}$, Jeff-X Zhou' ${ }^{1}$ Yu-Bo Yang ${ }^{3}$ and Xia-Xiang Jin ${ }^{4}$
}

\begin{abstract}
Background: Peritoneum metastasis of lung cancer is a rare event which, in addition to the peritoneum, usually involves multiple metastatic tissues. Here we report a case of a patient with lung adenosquamous cell carcinoma with the peritoneum as the sole distant metastatic site.

Case presentation: An 82-year-old Han Chinese man, in the teaching profession, was diagnosed with lung adenosquamous cell carcinoma in the upper lobe of his left lung with the involvement of ipsilateral hilar and mediastinal lymph nodes, and was initially staged as IIla $\left(\mathrm{CT}_{2} \mathrm{~N}_{2} \mathrm{M}_{0}\right)$. Molecular testing identified a mutation at KRAS G12A. Due to his poor physical condition, our patient was given gamma knife radiotherapy with a total dose of 28. 0 Gy. Two weeks later, our patient was diagnosed as peritoneal metastasis identified by using magnetic resonance imaging and confirmed with ascitic cytology and peritoneal histology. No other distant metastatic sites such as liver, brain, bone, paranephroi, and lungs were found. Subsequently, our patient received palliative intraperitoneal chemotherapy, and died within 2 months.
\end{abstract}

Conclusions: Our patient represented a rare case of lung adenosquamous cell carcinoma harboring the KRAS G12A mutation, which metastasized distantly to the peritoneum only, and progressed rapidly.

Keywords: Lung adenosquamous cell carcinoma, Peritoneum, Metastasis, KRAS mutation

\section{Background}

Metastasis is the predominant cause of cancer-related death. For lung cancer, $40-60 \%$ patients have metastasis at diagnosis [1]. The most common metastatic sites for lung cancer include the brain, bone, and liver, among others [2]. The incidence of peritoneal metastasis of lung cancer is less than $5 \%[3,4]$. For lung cancer patients with peritoneal metastases, the prognosis is poor with a overall survival time of usually less than 2 months [3-10]. Kirsten rat sarcoma $(K R A S)$ gene mutation is one of the key drivers for lung cancer development $[11,12]$, and is detected in $6-30 \%$ of non-small-cell lung cancer (NSCLC) patients [11, 13-16]. Patients with KRAS mutations can easily develop metastasis, and usually have poor prognosis [12, 17-19]. In this study, we report an

\footnotetext{
*Correspondence: ipec2012@126.com

${ }^{2}$ Department of Respiratory Medicine, Mingzhou Hospital, Zhejiang

University, No. 168 West Taian Road, Ningbo 315199, China

Full list of author information is available at the end of the article
}

uncommon case of a patient with lung adenosquamous cell carcinoma harboring KRAS G12A mutation with the peritoneum as the sole distant metastatic site.

\section{Case presentation}

An 82-year-old Han Chinese man, in the teaching profession, was admitted to our hospital for cough and bloody sputum. Our patient did not have fever, chest pain, dizziness, headache, nausea, or vomiting. He had been an ex-smoker for 30 years, had had hypertension for more than 60 years, and had a history of coronary heart disease with myocardial infarction 10 years earlier. A physical examination showed that his vital signs were stable without edema, cyanosis, or lymphadenopathy. Blood test results showed increases in the counts of white blood cells (WBC) and neutrophils. Serum levels of cytokeratin (CK)-19 fragment CYFRA21-1 and CA153 were $3.57 \mathrm{ng} / \mathrm{mL}$ and $47.2 \mathrm{U} / \mathrm{mL}$, respectively. A chest 

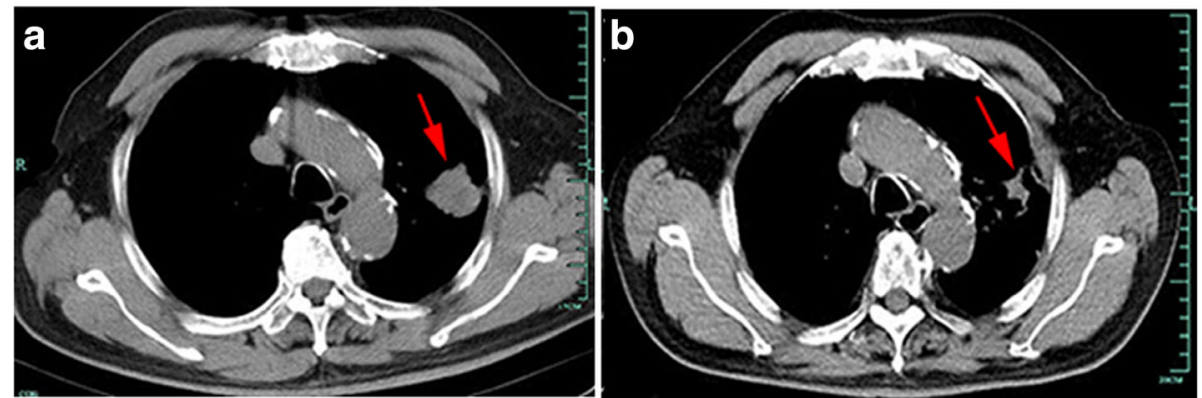

Fig. 1 a Chest computed tomography scan showed a mass in the upper lobe of the left lung (red arrow). $\mathbf{b}$ A chest computed tomography scan revealed that there was a reduction in the size of the mass in the upper lobe of the left lung after radiotherapy (red arrow)

computed tomography (CT) scan revealed a mass measuring $30 \times 30 \mathrm{~mm}$ in size in the upper lobe of his left lung with an enlarged left hilum (Fig. 1a). A positron emission tomography-computed tomography (PET-CT) scan showed three hypermetabolic lesions in the upper lobe of his left lung, left hilum, and left mediastinal lymph node (Fig. 2). No distant metastatic sites such as liver, brain, bone, paranephroi, lungs, and peritoneum were found. Bronchoscopy revealed an external compression of the upper lobe of his left lung. A CT-guided percutaneous lung biopsy was carried out, and the histological examination showed adenosquamous cell carcinoma. Immunohistochemical (IHC) studies showed positive outcomes in thyroid transcription factor-1 (TTF-1), napsin-A (NAP-A), CK-7, and P63, and negative outcome in CK-20 (Fig. 3). Deoxyribonucleic acid (DNA) sequencing showed that the tumor harbored KRAS G12A mutation. Based on the clinical findings, our patient was staged as IIIa $\left(\mathrm{T}_{2} \mathrm{~N}_{2} \mathrm{M}_{0}\right)$. Because of his poor physical condition, our patient was given palliative gamma knife radiotherapy with a total dose of 28.0 Gy for one cycle combined with anti-infective therapy. The WBC count returned to the normal range and his vital signs were stable following treatment, and our patient was discharged at his request after hospitalization for 43 days. Ten days after discharge, he was admitted to the hospital again because of weakness and anorexia. Blood test results showed increases in WBC and neutrophil counts. Serum levels of CA125, CA199, and CA153 were $474.3 \mathrm{U} / \mathrm{mL}, 467.5$ $\mathrm{U} / \mathrm{mL}$, and $28.4 \mathrm{U} / \mathrm{mL}$ respectively. A chest $\mathrm{CT}$ scan revealed that there was a reduction in the size of the original tumor in the upper lobe of his left lung (Fig. 1b). Abdominal enhanced magnetic resonance image (MRI) analysis showed multiple nodule-like lesions in the hepatic capsule, and was considered as metastatic carcinoma in the peritoneum (Fig. 4). Peritoneal effusion and peritoneum biopsy were evidenced, and a cytological examination of the ascites found clustered and scattered tumor cells; IHC of peritoneum tissue and ascite tumor cells showed

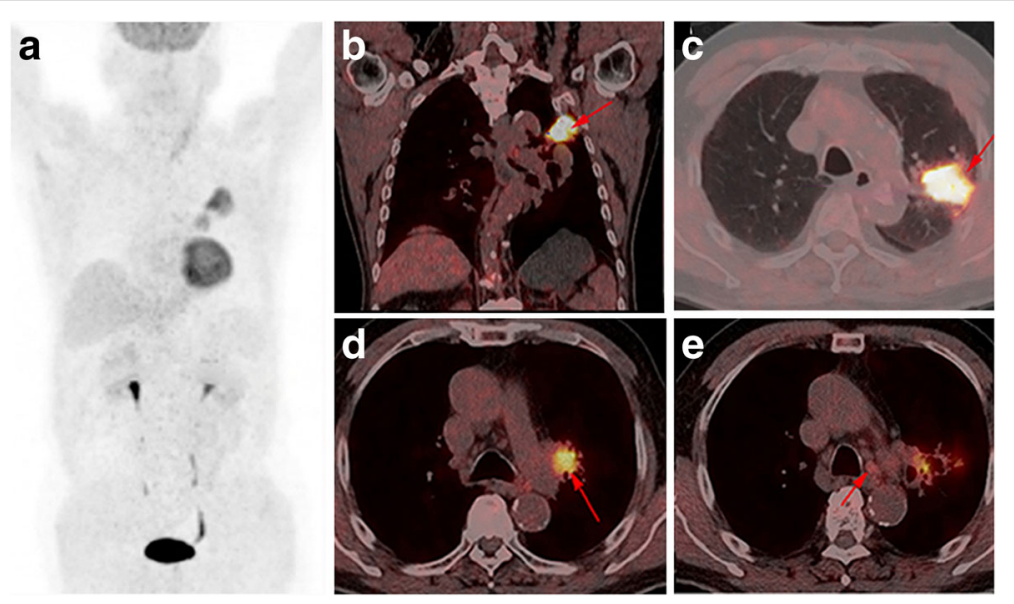

Fig. 2 a A positron emission tomography-computed tomography scan shows two hypermetabolic lesions in the upper lobe of the left lung and ipsilateral hilar lymph node. b-c Axial view of positron emission tomography-computed tomography scans for hypermetabolic lesion in the upper lobe of his left lung (red arrows), $\mathbf{d}$ in the left hilar lymph node (red arrow) and $\mathbf{e}$ in the left mediastinal lymph node (red arrow) 

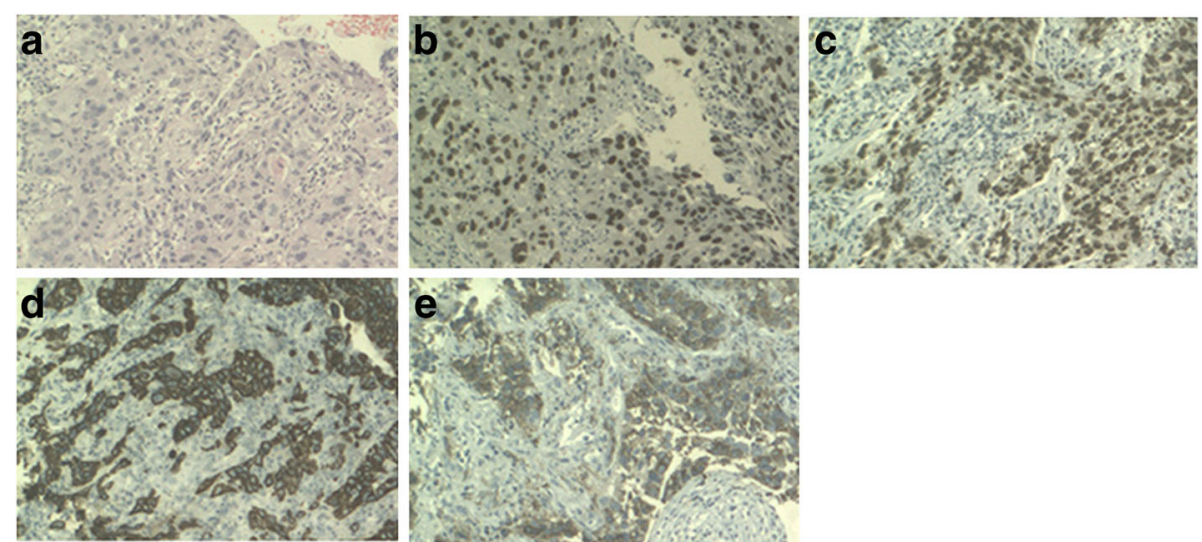

Fig. 3 a The tumor specimen shows adenosquamous cell carcinoma with moderate differentiation (hematoxylin and eosin staining, magnification $\times 40$ ). $\mathbf{b}$ Immunohistochemical of the tumor specimen is positive for p63 (positive in nucleus, magnification $\times 40$ ), $\mathbf{c}$ thyroid transcription factor-1 (positive in nucleus, magnification $\times 40$ ), $\mathbf{d}$ cytokeratin 7 (positive in cytoplasm, magnification $\times 40$ ), e napsin-A (positive in cytoplasm, magnification $\times 40)$

positive for CK-7 and TTF-1 (Fig. 5). No other distant metastasis was identified. Based on the progression of the disease, our patient was diagnosed with stage IV lung cancer with distant metastasis to the peritoneum $\left(\mathrm{cT}_{2} \mathrm{~N}_{2} \mathrm{M}_{1}\right)$. Accordingly, our patient received palliative intraperitoneal chemotherapy (cisplatin $40 \mathrm{mg}$ combined with recombinant human endostatin $45 \mathrm{mg}$ ) for one time. Unfortunately, no improvements were achieved and our patient died 11 days after readmission (Table 1 ).

\section{Discussion}

Peritoneum is a common metastatic site for gastric cancer [20], colorectal cancer [21], and ovarian cancer [22], but uncommon for lung cancer with its

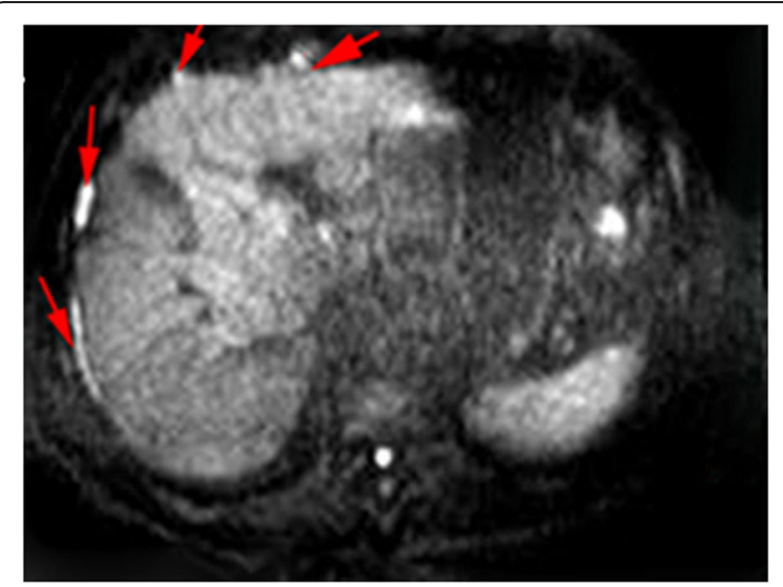

Fig. 4 Abdominal enhanced magnetic resonance image analysis showed multiple nodule-like lesions in the hepatic capsule (red arrows) incidence rate about $1-5 \%[3,4]$. In the reported cases involving peritoneal metastasis of lung cancer, there are usually multiple other distant metastatic tissues including brain, liver, and so on [4]. In the present case, it is reported as a lung adenosquamous cell carcinoma with peritoneal metastasis as the sole distant metastatic site, which was different from what was reported previously in which the pathological type included adenocarcinoma, squamous cell carcinoma, and large cell carcinoma [3, 4].

The patient in the present case had rapid progression in his clinical course. There may be several reasons underlying the rapid progression of this disease. First of all, his general condition, including his age, hypertension, infection, and so on, had limited the treatment options. As a result, only palliative radiotherapy was administrated. Second, the pathological type of adenosquamous cell carcinoma may also have contributed to the rapid worsening of our patient's condition. It has been reported that adenosquamous cell carcinoma of the lung possesses strong invasion ability and usually metastasizes at an early stage [23-25], and peritoneal metastasis is usually followed by particularly poor prognosis [3, 4, 7]. The third, genetic alterations such as KRAS mutations can increase the activities of matrix metalloproteases, cysteine proteases, serine proteases, urokinase plasminogen activator, and enzymes responsible for tumor invasion and metastasis [26-28]. In the present case, the mutation in KRAS may have played a pivotal role in the metastasis of lung cancer. Li et al. reported a case of lung squamous cell carcinoma with BRAF V600E and KRAS G12A mutations with peritoneal metastasis [29]. In addition, Pal $S$ et al. 


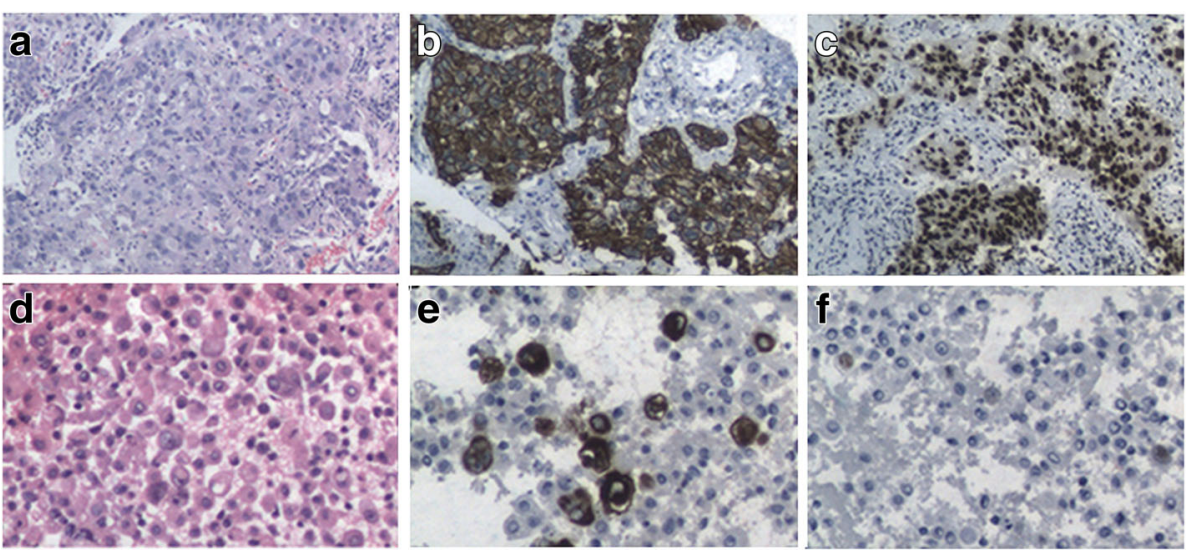

Fig. 5 a Cytological examination of peritoneum tissue (hematoxylin and eosin staining, magnification $\times 40$ ). $\mathbf{b}$ Immunohistochemical of peritoneum tissue showed positive for cytokeratin 7 (magnification $\times 40$ ) and $\mathbf{c}$ thyroid transcription factor-1 (magnification $\times 40$ ). $\mathbf{d}$ Cytological examination of ascites tumor cells (hematoxylin and eosin staining, magnification $\times 100$ ). e Immunohistochemistry of ascite tumor cells showed positive for cytokeratin 7 (magnification $\times 100$ ) and $\mathbf{f}$ thyroid transcription factor-1 (magnification $\times 100$ )

reported that lung cancer with KRAS mutation had an increased incidence of distant metastasis [30].

\section{Conclusions}

In summary, according to the present case and reported literature, lung adenosquamous cell carcinoma with KRAS mutations has high susceptibility to distant metastasis including peritoneal metastasis and a very rapid progression of clinical course. Sometimes the

Table 1 Timeline of the patient

\begin{tabular}{|c|c|c|}
\hline Dates & Course & Events \\
\hline $\begin{array}{l}\text { About Mar 28, } \\
2016\end{array}$ & $\begin{array}{l}\text { At least day } \\
-10\end{array}$ & Onset \\
\hline Apr 7, 2016 & Day 1 & First hospitalization \\
\hline Apr 12, 2016 & Day 6 & Bronchoscopy \\
\hline Apr 15, 2016 & Day 9 & PET-CT \\
\hline Apr 25, 2016 & Day 19 & Lung biopsy \\
\hline May 6, 2016 & Day 30 & $\begin{array}{l}\text { Gamma knife radiotherapy } \\
\text { (started) }\end{array}$ \\
\hline May 19, 2016 & Day 43 & $\begin{array}{l}\text { Gamma knife radiotherapy } \\
\text { (ended) }\end{array}$ \\
\hline May 20, 2016 & Day 44 & KRAS G12A mutation reported \\
\hline May 20, 2016 & Day 44 & Hospital discharge \\
\hline May 30, 2016 & Day 54 & Readmission \\
\hline May 31, 2016 & Day 55 & Peritoneocentesis \\
\hline Jun 4, 2016 & Day 59 & MRI \\
\hline Jun 6, 2016 & Day 61 & Peritoneal biopsy \\
\hline Jun 8, 2016 & Day 63 & Intraperitoneal chemotherapy \\
\hline Jun 10, 2016 & Day 65 & Died \\
\hline
\end{tabular}

PET-CT positron emission tomography-computed tomography, KRAS Kirsten rat sarcoma, MRI magnetic resonance imaging peritoneum may be the sole distant metastatic site and be followed by particularly poor prognosis.

\section{Abbreviations}

CA: Carbohydrate antigen; CK: Cytokeratin; CT: Computed tomography; CYFRA21-1: Cytokeratin 19 fragment; DNA: Deoxyribonucleic acid; Gy: Gray; IHC: Immunohistochemical; KRAS: Kirsten rat sarcoma; MRI: Magnetic resonance image; NAP-A: Napsin-A; NSCLC: Non-small-cell lung cancer; PETCT: Positron emission tomography-computed tomography; TTF-1: Thyroid transcription factor-1; WBC: White blood cells

\section{Acknowledgements}

The authors wish to acknowledge the support staff of $113^{\text {th }}$ Hospital of Chinese People's Liberation Army (PLA).

\section{Funding}

No funding was received for this study.

\section{Availability of data and materials}

Not applicable.

\section{Patient perspective \\ Not applicable.}

\section{Authors' contributions}

PY followed up the patient, compiled the case details, and wrote the manuscript. W-LL, Y-BY and PY carried out the therapeutic regimen. W-LL reported on imaging and provided the CT/MRI figures. X-XJ reported on histology and immunohistochemistry and provided images for pathology figures. W-LL and J-XZ revised and restructured the manuscript. All authors read and approved the final manuscript.

\section{Ethics approval and consent to participate}

The study protocol was approved by the Ethical committee of Ningbo $113^{\text {th }}$ Hospital of Chinese People's Liberation Army (PLA).

\section{Consent for publication}

Written informed consent was obtained from the patient's next-of-kin for publication of this case report and any accompanying images. A copy of the written consent is available for review by the Editor-in-Chief of this journal.

\section{Competing interests}

The authors declare that they have no competing interests. 


\section{Publisher's Note}

Springer Nature remains neutral with regard to jurisdictional claims in published maps and institutional affiliations.

\section{Author details}

'Department of Pathology, Ningbo University School of Medicine, Ningbo, China. ${ }^{2}$ Department of Respiratory Medicine, Mingzhou Hospital, Zhejiang University, No. 168 West Taian Road, Ningbo 315199, China. ${ }^{3}$ Department of Respiratory Medicine, 113th Hospital of PLA, No. 377 East Zhongshan Road, Ningbo 315040, China. ${ }^{4}$ Department of Pathology, 113th Hospital of PLA, No. 377 East Zhongshan Road, Ningbo 315040, China.

Received: 10 May 2017 Accepted: 20 August 2017

Published online: 27 September 2017

\section{References}

1. Jemal A, Siegel R, Xu J, et al. Cancer statistics, 2010. CA Cancer J Clin. 2010; 60:277-300

2. Quint LE, Tummala S, Brisson LJ, et al. Distribution of distant metastases from newly diagnosed non-small cell lung cancer. Ann Thorac Surg. 1996; 62:246-50.

3. Su HT, Tsai CM, Perng RP. Peritoneal carcinomatosis in lung cancer. Respirology. 2008;13:465-7

4. Satoh H, Ishikawa H, Yamashita YT, et al. Peritoneal carcinomatosis in lung cancer patients. Oncol Rep. 2001;8:1305-7.

5. Bazine A, Fetohi M, Khmamouch MR, et al. An unusual case of isolated peritoneal metastases from lung adenocarcinoma. Case Rep Oncol. 2014;7:600-4.

6. Tanriverdi O, Barutca S, Meydan N. Relapse with isolated peritoneal metastasis in lung adenocarcinoma: case report and review of the literature. Contemp Oncol (Pozn). 2012;16:586-9.

7. Hanane K, Salma B, Khadija B, et al. Peritoneal carcinomatosis, an unusual and only site of metastasis from lung adenocarcinoma. Pan Afr Med J. 2016;23:60.

8. Sereno M, Rodriguez-Esteban I, Gomez-Raposo C, et al. Lung cancer and peritoneal carcinomatosis. Oncol Lett. 2013;6:705-8.

9. Song $\mathrm{SH}, \mathrm{Oh}$ YJ, Kim YN, et al. Squamous cell carcinoma of the lung with simultaneous metastases to peritoneum and skeletal muscle. Thorac Cancer. 2014:5:101-3.

10. Du C, Li Z, Wang Z, et al. Stereotactic aspiration combined with gamma knife radiosurgery for the treatment of cystic brainstem metastasis originating from lung adenosquamous carcinoma: A case report. Oncol Lett. 2015;9:1607-13.

11. Yu HA, Sima CS, Shen R, et al. Prognostic impact of KRAS mutation subtypes in 677 patients with metastatic lung adenocarcinomas. J Thorac Oncol. 2015;10:431-7

12. Martin P, Leighl NB, Tsao MS, et al. KRAS mutations as prognostic and predictive markers in non-small cell lung cancer. J Thorac Oncol. 2013;8:530-42.

13. Roberts PJ, Stinchcombe TE, Der CJ, et al. Personalized medicine in non-small-cell lung cancer: is KRAS a useful marker in selecting patients for epidermal growth factor receptor-targeted therapy? J Clin Oncol. 2010;28:4769-77.

14. Zheng D, Wang $R$, Zhang $Y$, et al. The prevalence and prognostic significance of KRAS mutation subtypes in lung adenocarcinomas from Chinese populations. Onco Targets Ther. 2016;9:833-43.

15. Riely GJ, Kris MG, Rosenbaum D, et al. Frequency and distinctive spectrum of KRAS mutations in never smokers with lung adenocarcinoma. Clin Cancer Res. 2008;14:5731-4.

16. Gou LY, Niu FY, Wu YL, et al. Differences in driver genes between smokingrelated and non-smoking-related lung cancer in the Chinese population. Cancer. 2015:121 Suppl 17:3069-79.

17. Massarelli E, Varella-Garcia M, Tang X, et al. KRAS mutation is an important predictor of resistance to therapy with epidermal growth factor receptor tyrosine kinase inhibitors in non-small-cell lung cancer. Clin Cancer Res. 2007;13:2890-6

18. Ricciuti B, Leonardi GC, Metro G, et al. Targeting the KRAS variant for treatment of non-small cell lung cancer: potential therapeutic applications. Expert Rev Respir Med. 2016:10:53-68

19. Marabese M, Ganzinelli M, Garassino MC, et al. KRAS mutations affect prognosis of non-small-cell lung cancer patients treated with first-line platinum containing chemotherapy. Oncotarget. 2015;6:34014-22.

20. Riihimaki $M$, Hemminki $A$, Sundquist $K$, et al. Metastatic spread in patients with gastric cancer. Oncotarget. 2016;7:52307-16.
21. Riihimaki M, Hemminki A, Sundquist J, et al. Patterns of metastasis in colon and rectal cancer. Sci Rep. 2016:6:29765.

22. Pereira A, Perez-Medina T, Magrina JF, et al. International Federation of gynecology and obstetrics staging classification for cancer of the ovary, fallopian tube, and peritoneum: estimation of survival in patients with node-positive epithelial ovarian cancer. Int J Gynecol Cancer. 2015;25:49-54.

23. Sridhar KS, Bounassi MJ, Raub Jr W, et al. Clinical features of adenosquamous lung carcinoma in 127 patients. Am Rev Respir Dis. 1990;142:19-23.

24. Shimizu J, Oda M, Hayashi Y, et al. A clinicopathologic study of resected cases of adenosquamous carcinoma of the lung. Chest. 1996;109:989-94.

25. Maeda H, Matsumura A, Kawabata T, et al. Adenosquamous carcinoma of the lung: surgical results as compared with squamous cell and adenocarcinoma cases. Eur J Cardiothorac Surg. 2012:41:357-61.

26. Jankun J, Maher VM, McCormick JJ. Malignant transformation of human fibroblasts correlates with increased activity of receptor-bound plasminogen activator. Cancer Res. 1991;51:1221-6.

27. Buo L, Meling Gl, Karlsrud TS, et al. Antigen levels of urokinase plasminogen activator and its receptor at the tumor-host interface of colorectal adenocarcinomas are related to tumor aggressiveness. Hum Pathol. 1995:26:1133-8.

28. Yamamoto $\mathrm{H}$, Itoh $\mathrm{F}$, Senota $\mathrm{A}$, et al. Expression of matrix metalloproteinase matrilysin (MMP-7) was induced by activated Ki-ras via AP-1 activation in SW1417 colon cancer cells. J Clin Lab Anal. 1995;9:297-301.

29. Li B, Lu JC, He D, et al. Rapid onset lung squamous cell carcinoma with prominent peritoneal carcinomatosis and an eosinophilic leukemoid reaction, with coexistence of the BRAF V600E and oncogenic KRAS G12A mutations: a case report. Oncol Lett. 2014;8:589-93.

30. Pal S, Amin PJ, Sainis KB, et al. Potential Role of TRAlL in metastasis of mutant KRAS expressing lung adenocarcinoma. Cancer Microenviron. 2016; 9:77-84.

\section{Submit your next manuscript to BioMed Central and we will help you at every step:}

- We accept pre-submission inquiries

- Our selector tool helps you to find the most relevant journal

- We provide round the clock customer support

- Convenient online submission

- Thorough peer review

- Inclusion in PubMed and all major indexing services

- Maximum visibility for your research

Submit your manuscript at www.biomedcentral.com/submit 